\title{
Conhecimento e metáfora
}

\section{Gustavo Bernardo}

A teoria da literatura freqüenta um terreno usualmente acidentado, atravessado por aporias. Uma aporia indica a dificuldade insuperável de um raciocínio, ou o conflito resultante da igualdade de raciocínios opostos entre si. $\mathrm{O}$ adjetivo "aporético" refere-se a tudo o que não tem solução à vista, ou ao ato de se valorizar o exame de um problema mais que sua resolução. Fazem parte do campo semântico de "aporia" as palavras incerteza e impasse*. O campo da teoria da literatura é rico em aporias, ou raciocínios aporéticos, em razão da dificuldade de chegar a certezas demonstráveis. Supomos que isso ocorra menos por indigência teórica que pelo caráter intrínseco dessa teoria: há nela uma ambigüidade dilemática que a constitui.

Encontramos a mesma ambigüidade, e freqüentemente dilemática, na mais conhecida das figuras de linguagem: a metáfora. Através de sua constituição, podemos, se não resolver, explorar dilemas e aporias da literatura. Folheando nossos antigos cadernos escolares, lembramos que a metáfora diz uma coisa por outra, designando um objeto mediante uma palavra que designa outro objeto, que, por sua vez, teria com o primeiro uma relação de semelhança. Por exemplo: "ele tem uma vontade de ferro" fala de uma vontade tão forte quanto se supõe que seja o ferro. Por isso, "bem saber descobrir as metáforas significa bem se aperceber das semelhanças"*. Descobrir a metáfora adequada facilita se aproximar, por expressão o mais semelhante possível, daquele elemento da realidade que nos interessa.

Ser semelhante, porém, não é ser igual - o que, sendo óbvio, nem sempre se lembra. A metáfora não pode ser igual ao que designa: dizer "esse ferro é um ferro" implica dizer nada. Umberto Eco joga bem com a semelhança-dessemelhança entre a metáfora e aquilo que ela designa: "existem poderes imateriais, não avaliáveis a peso, mas que de alguma forma pesam"*. A expressão "de alguma forma" mostra que o atributo "peso" não se aplica exata, mas sim aproxi-

-(Japiassu, Hilton \& Marcon. des, Danilo. Dicionário básico de filosofia. Rio de Janeiro: Jorge Zahar Editor, 1990: 23.)

'(Aristóteles. Poética. Tradu. ção de Eudoro de Souza. São Paulo: Ars Poetica, 1992: 119.)
"(Eco, Umberto. Sobre a literatura. Tradução de Eliana Aguiar. Rio de Janeiro: Re. cord, 2000: 39.) 
(Costa Lima, Luiz. Mímesis e modernidade: formas das sombras. São Paulo: Paz Terra, 2003: 46.)
"(Riedel, Dirce Côrtes. Me táfora, o espelho de Macha do de Assis. Rio de Janeiro: Francisco Alves, 1974: 14.)
"(Booth, Wayne. "A metáfo ra como retórica: o proble. ma da avaliação". Em: Sacks, Sheldon (org.). Da metáfora. Tradução de Francisco Wie \& outros. Campinas: Pon tes, 1992: 55. madamente. De modo equivalente, os eventos que as narrativas nos apresentam se pretendem verossímeis, isto é, semelhantes à verdade, o que também significa: eles não podem e não devem ser iguais à verdade. Isso significa que podemos tão-somente nos aproximar da verdade, mas não temos como chegar "lá”? Em alguns contextos, e possivelmente nos mais importantes, a resposta é "sim”. Muitos filósofos e lingüistas consideram que toda a linguagem seria metafórica, se as palavras não são as coisas que designam - "entre a palavra e a realidade, há uma tamanha rede de causações que nunca a palavra se torna transparente à realidade"*.

Nesse sentido, nossos cadernos escolares talvez não contenham a melhor definição de metáfora, porque a definição escolar de metáfora como "uma comparação elíptica ou subentendida” seria inadequada. Quem o diz é Dirce Côrtes Riedel, ao estudar as metáforas de Machado de Assis. Para ela, a metáfora não exprime uma comparação em menor número de signos, ao contrário: a metáfora diz outra coisa como a comparação não seria capaz, porque se transgridem os interditos combinatórios do bom senso e do senso comum*. Ao combinar no mínimo dois sentidos num único signo, a metáfora se constitui como um paradoxo que mostra o sentido tomando sempre duas direções ao mesmo tempo. Rompe-se, então, a linearidade do discurso e se abalam as pressuposições da identidade.

O paradoxo faz Wayne Booth lembrar um antigo ponto de vista teológico, segundo o qual não apenas toda a linguagem seria metafórica, como toda a nossa vida não passaria de uma metáfora - no caso, metáfora da verdade divina*. Por trás desse ponto de vista teológico, encontra-se a concepção platônica: o que vemos do mundo é um duplo ou uma sombra. A linguagem se refere a essa sombra, não à luz ou à coisa em si. Por isso, Platão considera a poesia perigosa: linguagem que se assume desde o princípio metafórica, à medida que ela mimetizaria o que já seria mímese do real ele mesmo, a poesia nos afastaria do real a ponto de nos mergulhar no fundo do engodo. Mas Mário Chamie, como muitos poetas, naturalmente reage a Platão: na primeira estrofe do poema "Metáfora Assassina", ele prega a necessidade de não se fugir da metáfora mesmo quando ela parece cometer um crime contra a realidade: 


$$
\begin{aligned}
& \text { Se alguém disser } \\
& \text { que uma zona de sombra } \\
& \text { encobre algum desejo } \\
& \text { facínora, } \\
& \text { enfrente a hora déspota } \\
& \text { e cínica da fuga: } \\
& \text { - não fuja da metáfora, } \\
& \text { sua pura pedra única.* }
\end{aligned}
$$

Em situações-limite, cabe enfrentar a metáfora e sua ambigüidade constitutiva, sem dela fugir em nome da necessidade da exatidão. Uma vez que aceitamos toda linguagem como metafórica, precisamos suspeitar de que a linguagem seja eminentemente equívoca (quando desfazemos um equívoco, provocamos dois outros no lugar). Como a literatura é o campo em que as metáforas não se escondem, podemos ousar considerar a teoria da literatura como o discurso privilegiado para lidar com a realidade. Entretanto nossa modesta primeira pessoa do plural não traduz exatamente uma unanimidade da área, porque parte respeitável da crítica literária ainda considera arriscado misturar a ficção com o referente, isto é, a literatura com o mundo real. A noção de ficção convida "a não confundir texto e referente"*. Seria da mesma ordem a distinção entre escritor e narrador: o primeiro existiu ou existe no mundo real, enquanto o segundo só existe no texto e através dele. A distinção, nesse caso, permite ao escritor a liberdade de contar histórias por meio de múltiplas identidades e perspectivas. Segundo a mesma lógica, faz-se igualmente necessário distinguir "leitor" - o ser humano que se situa fora do texto e lê a obra - de "narratário" - aquele que dentro do texto escuta ou lê a história que é contada. Essa distinção particular faculta ao escritor outra liberdade essencial: "a de construir textualmente a imagem de seu leitor e de jogar com ele, seja qual for o público real que leia o livro"*.

Distinções técnicas como essas são pertinentes, é claro, mas correm outro risco: o de prender o esforço teórico em apenas duas grandes categorias - de um lado, a ficção (o texto, o narrador, o narratário) e, do outro, o mundo real (o referente, o escritor, o leitor). Supomos, todavia, que nem a realidade nem a ficção sejam tão simples.

O escritor português José Saramago costuma fazer palestras em Faculdades de Letras reclamando da distinção entre autor e narrador, tão invocada pelos professores de
'(Chamie, Mário. Horizonte de esgrimas. Ribeirão Preto: Funpec, 2002: 101.)

'(Reuter, Yves. A análise da narrativa: o texto, a ficção e a narração. Tradução de Mario Pontes. Rio de Janeiro: Difel, 2002: 18.) 
"(citado por Harries, Karsten. cia". Em:Sacks, Sheldon (org. Da metáfora. Ob.cit.: 78.) "(citado por David, Mariano Gazineu. Arte e literatura no pensamento de Gilles Deleu 113.) teoria da literatura. Ele considera que subjaz a essa separação uma espécie de desresponsabilização do escritor, que a partir da separação se torna uma espécie de causa mecânica da obra. Segundo Saramago, mesmo quando seu narrador é uma mulher, é ele quem lá está, no que pensa ser a perspectiva de uma mulher. $\mathrm{O}$ que o escritor recusa é a redução do fazer literário a uma técnica e daí a esquemas. Escrevo, diz ele, porque tenho algo a dizer e sou responsável pelo que digo; o leitor que me lê, lê uma obra assinada. Para atender salomonicamente a Reuter e a Saramago, diríamos que o narrador é também o escritor, mas é ainda mais que o escritor, porque transcende sua perspectiva de sujeito empírico ampliando-a através da figuração imaginária. Da mesma maneira, o leitor não é o narratário idealizado pelo escritor, mas se torna um pouco esse narratário, à proporção que a leitura o modifica.

Mesmo que a ficção não se confunda totalmente com a realidade, há diversas regiões de sombra e de interseção que provocam confusões significativas, como aquelas que sucedem nos breves intervalos entre sonho e vigília. Essas regiões não são imóveis, e por isso não conseguimos demarcá-las facilmente. Uma teoria da ficção interessa a quem deseja compreender não apenas a literatura, como também as regiões de sombra. A metáfora, potência ambígua, tanto ilumina quanto esconde a sombra. Por isso, mesmo no campo da teoria da literatura, há quem negue, como Jonathan Culler, que o poder da literatura resida na metáfora, afirmando ser "justamente a resistência da literatura à metáfora"* a fonte desse poder. Kafka concordaria com Culler; o escritor tcheco sentia que as metáforas liquefaziam o sentido e, com o sentido, as coisas, transformando a linguagem numa rede de fios impessoais a manipular fantoches. Escreveu, em 1921: "as metáforas são uma das coisas que me fazem perder a esperança na literatura"*.

Sabia, no entanto, que não deixaria de fazer metáforas apenas porque quisesse; seria necessário driblar o caráter metafórico da linguagem humana. Por isso, Kafka abre seu romance mais conhecido, $A$ metamorfose, com a seguinte frase: "Quando certa manhã Gregor Samsa acordou de sonhos intranqüilos, encontrou-se em sua cama metamorfoseado num inseto monstruoso"*. Ora, essa frase contém uma metáfora. 
A partir daí, porém, a metáfora "inseto $\leftrightarrow$ Gregor" passa a ser narrada como se não fosse metáfora: à medida que Gregor se "insetiza", seus familiares e o leitor vão lidando com aquele inseto "real" (embora gigantesco), como se sua existência não fosse absurda, ou seja, como se não houvesse mais a metáfora. Os acontecimentos são narrados metonimicamente. O inseto-Gregor se torna parte lógica e "natural" de outra coisa maior - por exemplo, do processo que o explorou e o alienou.

A restrição de Culler e a solução de Kafka servem para problematizar a figura da metáfora e a teoria da ficção. Sentimos que nos aproximamos da realidade com as palavras, mas não temos como envolver a realidade toda. Há sempre algum significado que falta. Esse significado que falta terá levado Slavoj Zizek a encontrar uma "metáfora da metáfora" em um popular produto europeu chamado Kinder Surprise (no Brasil, "Kinder Ovo"). Trata-se de ovos ocos feitos de chocolate e embrulhados em papel colorido: depois de desembrulhar o ovo, quebra-se a casca e se descobre no interior um pequeno brinquedo plástico, ou pequenas partes com as quais se monta um brinquedo. A criança que desembrulha esse ovo quebra-o sem se importar em comer o chocolate. Mostra-se mais interessada no brinquedo. $\mathrm{O}$ vazio material no centro do ovo representa a lacuna estrutural em razão da qual nenhum bem é "realmente aquilo": nenhum produto satisfaz a expectativa que desperta*. Nos termos do desejo, queremos sempre outra coisa que não "isto", outra coisa que não está "aqui”. Nos termos da linguagem, falamos menos do que queremos (nunca se diz tudo) e, ao mesmo tempo, mais do que pretendíamos (sempre se fala demais): assim nascem os equívocos e os mal-entendidos. A metáfora também é uma promessa (ou uma aposta) dentro de um ovo, mas muitos não acreditam nessa promessa - ou não querem bancar essa aposta.

Hobbes considerava a metáfora um dos piores abusos da linguagem, porque recorre a palavras "com sentidos diferentes daqueles para os quais foram inventadas", conduzindo os outros ao engano. Se palavras inconstantes não podem servir de base para o raciocínio, o mesmo se deve dizer das metáforas. Elas só são menos perigosas que as mentiras porque, ao menos, proclamam sua inconstância*. Cientistas e

"(Hobbes citado por Cohen, Ted. "A metáfora e o cultivo de intimidade". Em: Sacks, Ob. cit.: 10.) 
(Bunge, Mario. Dicionário de filosofia. Tradução de Gita Guinsburg. São Paulo: Pers. pectiva, 2002: 244.) "(citado por Gardner, Martin. O umbigo de Adão: sobre as maiores fraudes da ciência. Tradução de Beatriz Sidou. 171.)

(citada por Sokal, Alan Bricmont, Jean. Imposturas intelectuais: 0 abuso da ciência pelos filósofos pós-moder nos. Tradução de Max Altman. Rio de Janeiro: Record, 1999 109.) professores repetem as palavras de Hobbes e consideram as metáforas no mínimo frívolas, quiçá perigosas. Mario Bunge, físico e professor de filosofia, considera a metáfora adequada apenas à poesia, ao pensamento arcaico, ao discurso político sob tirania e à elucubração pós-moderna: "enquanto as teorias científicas são testáveis no tocante às suas verdades, as metáforas, no melhor dos casos, são sugestivas, e no pior deles causam confusão"*.

A posição extremada de Bunge é partilhada por vários cientistas, entre eles aquele que ficou conhecido por abrir uma polêmica rasgada com filósofos e críticos literários franceses: Alan Sokal. Em 1996, a revista Social Text publicou um artigo de Sokal intitulado: "A transgressão das fronteiras: para uma hermenêutica transformadora da gravidade quântica”. $\mathrm{O}$ artigo era, na verdade, um embuste, parodiando satiricamente os filósofos relativistas que usam termos científicos para sustentar que a realidade não passa de um constructo social e lingüístico. A parte mais engraçada do ensaio é a conclusão: segundo esta, "a ciência deve emancipar-se da matemática clássica antes de se tornar um instrumento concreto da práxis política progressista; como as constantes matemáticas são meros constructos sociais, nem mesmo o número $\pi$ é fixo, mas sim uma variável culturalmente determinada"*.

O artigo de Sokal gerou a expressão "sokal neles!", que passou a ser usada por cientistas céticos para se referirem a manifestações pós-modernas de relativismo extremado. Em função das muitas reações, Alan escreveu junto com o belga Jean Bricmont o livro Imposturas intelectuais, cujo subtítulo era "o abuso da ciência pelos filósofos pós-modernos". No livro, criticam frontalmente Jacques Lacan, Julia Kristeva, Luce Irigaray, Bruno Latour, Jean Baudrillard, Gilles Deleuze, Félix Guattari e Paul Virilio. Uma das críticas mais duras coube à feminista Irigaray e, por extensão, a boa parte dos chamados estudos culturais que enfatizam a perspectiva do gênero. Irigaray considera que, mesmo quando o conhecimento se pretende objetivo, a ciência sempre apresenta certas escolhas "particularmente determinadas pelo sexo dos eruditas envolvidos"*. Por isso, ela teria levantado a hipótese, de fato algo estrambótica, de que a equação $\mathrm{E}=\mathrm{MC}^{2}$ fosse sexuada, ou seja, machista: "o que parece indicar a possível 
natureza sexuada da equação não é precisamente o seu uso em armas nucleares, mas sim o fato de ter privilegiado o mais rápido"*. Sokal, naturalmente, considera essa hipótese apenas ridícula.

A réplica mais violenta a Alan Sokal veio de Stanley Fish, em artigo chamado "A piada de mau-gosto do professor Sokal”. O artigo de Fish negava com veemência que os sociólogos especializados no estudo da ciência, ou os epistemólogos modernos, suspeitassem não haver nenhum mundo externo independente de observações; eles apenas tratam do que se diz sobre o mundo real, este sim, socialmente construído*. Para defender Sokal, o matemático Martin Gardner primeiro desqualificou o oponente: "Fish andou fascinado com o desconstrucionismo, um movimento passageiro meio idiota que substituiu o existencialismo e foi a última moda filosófica na França”* . Depois, desqualificou o próprio argumento do outro, considerando-o, no mínimo, manifestação de má-fé: Fish primeiro teria resolvido assombrar a todos, declarando que os peixes não são parte da natureza, mas sim entidades abstratas artificialmente produzidas pela linguagem humana; pressionado a se explicar, ele rapidamente teria tentado consertar a afirmativa esdrúxula, ao ressaltar que não se referia a peixes "reais" de águas reais, mas apenas à palavra "peixe"*.

Como em qualquer confronto, os adversários tentam pegar o ponto fraco um do outro, e por isso nem sempre desenvolvem bem o próprio ponto. A réplica de Fish a Sokal não é de fato muito forte, porque ele não soube fazê-la nos termos do outro. A defesa que Gardner faz de Sokal, no entanto, é mais fraca ainda, quer porque parte de um argumento ad hominem, evoluindo para um argumento ad philosophum deveras precário, quer porque torce completamente os termos da posição de Stanley Fish: o crítico apenas disse que o seu objeto de estudo era o discurso, inclusive o discurso científico, discurso este que não pode não ser socialmente construído.

As críticas de Gardner e Sokal à filosofia francesa dita pós-moderna tentam demoli-la por completo, sem paciência para refletir sobre a razão de sua importância. Na verdade, essa filosofia desenvolve uma forma peculiar de ceticismo, criticando radicalmente a ciência e a possibilidade de conhecimento objetivo e totalizante. Jacques Lacan, Jacques Derrida, 
"(Kurtz, Paul. The newskepticism: inquiry and reliable knowledge. New York: Buffalo, 1992: 65.)

"(Bunge, Mario. Dicionário de filosofia. São Paulo: Pers pectiva, 2002: 380.)
(Gardner, Martin. O umbigo de Adão. Ob. cit.: 174.)
Michel Foucault, Jean-François Lyotard e os demais rejeitaram a própria Modernidade, isto é, eles se mostraram céticos a respeito da confiança iluminista na razão humana e no progresso irreversível. Ora, pode-se dizer que os acontecimentos do século XX autorizam esse ceticismo que, como avalia Paul Kurtz, estende-se à crença humanista na autonomia do indivíduo e ao historicismo marxista*. O problema específico da crítica que se auto-intitula pós-moderna reside no abuso da terminologia científica por quem não a domina de fato e de direito. Um exemplo recorrente está em tomar o “princípio de indeterminação”, de Werner Heisenberg, como um princípio de incerteza em relação a todas as realidades observáveis. Mario Bunge explica por que chamar o teorema de Heisenberg de "princípio de incerteza” é um equívoco respeitável: o teorema, na verdade, declara que o espectro de variação da posição de um elétron, ou qualquer outro quanton, está inversamente relacionado com a amplitude de sua velocidade. Corolário: à proporção que a amplitude em posição se contrai, a amplitude de velocidade se expande, e viceversa. Ou seja: mesmo que o leigo não entenda o que isso quer dizer, não pode daí inferir qualquer relação a operações de medida ou à posição do observador*. Ora, o fato de o ceticismo filosófico e a teoria da literatura estabelecerem algo como "um princípio de incerteza” é perfeitamente válido, mas talvez seja o caso de não procurar legitimá-lo recorrendo à autoridade (para nós, sobrenatural) da mecânica quântica.

Os cientistas, de sua parte, poderiam eventualmente recorrer à sua proverbial dúvida metódica e ao fator de correção da ciência, para usá-los em relação à própria ciência. Gardner, por exemplo, sustenta: “o fato de a ciência se movimentar inexoravelmente para mais perto de encontrar a verdade objetiva só pode ser negado por filósofos excêntricos, críticos literários ingênuos e cientistas sociais desorientados"*. O fantástico sucesso da ciência para explicar, prever e desenvolver inacreditáveis progressos tecnológicos seria a prova cabal de que os cientistas estão aprendendo cada vez mais sobre como o universo se comporta. Ora, essa defesa da ciência constitui manifestação explícita de fé, que, nesse caso específico, implica uma contradição em termos. As expressões "fantástico sucesso da ciência” e "inacreditáveis progressos 
tecnológicos" parecem valorizar igualmente o combate às doenças e as armas químicas, a exploração espacial e a bomba atômica, sem atinar que armas de destruição em massa, bem como campos de concentração, já poderiam se encontrar no "programa" da ciência e do pensamento ocidentais.

Na verdade, Gardner e Sokal desqualificam a metáfora como instrumento de conhecimento, mas usam metáforas para combater melhor seus adversários. Dizer, como diz Gardner, que a ciência se movimenta "inexoravelmente para cada vez mais perto de encontrar a verdade objetiva" implica uma metáfora ousada, colando a ciência à flecha do tempo que se move sempre para a frente. Ora, isso é, na minha modesta opinião não-científica, uma besteira - e não me incluo entre os "filósofos excêntricos, críticos literários ingênuos e cientistas sociais desorientados". A crença na irreversibilidade do progresso não é mais partilhada sequer pelos cientistas. A ciência, como tudo o mais, anda ora para frente, ora para trás, ora para os lados, ora para cima e ora para baixo - às vezes, chega a dar um nó nos próprios pés e toma um tombo. $\mathrm{O}$ argumento de que a ciência possui um fator de correção reforça a minha tese mais que a de Gardner: o próprio fator de correção contesta a inexorabilidade do movimento científico. Acresce que, sempre que o fator é aplicado e a ciência corrige seu rumo, deixa-se para trás uma série de cobaias, animais e humanas, mutiladas ou mortas.

Em outro momento, Gardner atenua suas afirmações peremptórias, permitindo-se perguntar: "conforme a ciência aumenta firmemente seu conhecimento da natureza, jamais chegando a uma certeza absoluta, mas sempre se aproximando cada vez mais da compreensão da natureza, será que algum dia ela descobrirá tudo?’*. A resposta do matemático, felizmente, é negativa: jamais saberemos, por exemplo, todos os decimais de $\Sigma$. Mas creio que ele está errado ao dizer que a ciência se aproxima cada vez mais da compreensão global da natureza: enquanto não soubermos nada menos que tudo, não temos como saber a que distância estamos do conhecimento total. Como nunca saberemos "tudo", nunca poderemos saber se estamos nos aproximando ou nos distanciando do conhecimento de toda a natureza. Pode-se ainda afirmar, também sem o poder demonstrar, que outro paradoxo seria verdadeiro: quanto mais se sabe, menos se sabe. Ou: quanto 
"(Asimov citado por Gardner, Martin. O umbigo de Adão. Ob. cit.: 348.)
"(Man, Paul de. "A epistemo logia da metáfora". Em: Sacks, Sheldon (org.). Da metáfora. Ob.cit.: 19.)
"(:26.)

(Williams, Raymond. Tragé dia moderna. Tradução de Betina Bischof. São Paulo: Cosac \& Naify, 2002: 154.) mais se sabe, mais se sabe o quanto ainda falta saber; mais aumenta a consciência da extensão da nossa ignorância. Em termos livrescos, isto é, nos nossos termos: quanto mais lemos, mais aumenta a lista dos livros que ainda não lemos esse movimento é que seria inexorável.

Posso ainda usar Gardner contra Gardner em outro instante: depois de desqualificar completamente qualquer concepção construtivista do conhecimento, o matemático aceita que a teoria das supercordas seja hoje a última palavra em Física, embora ainda não se possa demonstrá-la cabalmente. Mas, ao se perguntar de que seriam feitas tais supercordas, responde como um construtivista militante: as supercordas seriam “puros constructos matemáticos. Se as supercordas são o fim da linha, tudo o que existe em nosso universo, inclusive você e eu, é um constructo matemático. É como disse um amigo meu: o universo parece ser feito de nada, mas, sabe-se lá como, consegue existir”* Para reforçar essa posição contra si mesmo, o próprio Gardner cita Isaac Asimov, cientista mais conhecido como escritor de ficção científica: "acredito que o conhecimento científico tem propriedades fractais; não importa o quanto aprendamos, seja o que for que sobrar, por menor que possa parecer, é tão infinitamente complexo quanto o foi o começo do todo. Acho que este é o segredo do universo"*. Portanto, se o incognoscível não desaparece, isso significa que em todo lugar nos cerca o tal do mysterium tremendum.

Se, como vimos, Hobbes considerava a metáfora um dos piores abusos da linguagem, podemos perceber que não somente os cientistas combatem a metáfora, ainda que usando metáforas. Paul de Man comenta o esforço da filosofia para controlar todo raciocínio metafórico*. Ele vê, de fato, um perigo: mesmo que as metáforas tenham a atenuante de se proclamarem como tal, com o tempo elas tendem a se transformar em catacreses, ou seja, em metáforas gastas. Então, “algo monstruoso espreita na mais inocente das catacreses: quando falamos das pernas de uma mesa ou da face de uma montanha, a catacrese já se transforma em prosopopéia e começamos a perceber um mundo povoado por fantasmas e monstros em potencial"*. Esses monstros produzem os dogmas: "aquilo a que chamamos dogma é o tecido morto de crenças gastas e desconexas"*. 
A catacrese que se transforma em prosopopéia e produz o dogma faz uma volta e, curiosamente, recupera a face estética, ainda que esteticamente feia, na forma do kitsch. O termo alemão vem do inglês sketch, apelidando ilustrações de cartões postais feitos sob medida para turistas norte-americanos. Mais tarde, designou toda ilustração barata (e xaroposa, piegas, escorregadia) feita em série. Usa-se ainda outro termo alemão bem mais agressivo para designar essa produção: Schmalz, que significa "banha”. Schmalz define bem, segundo Anatol Rosenfeld, "a qualidade viscosa desta arte postiça, sua maneira pegajosa de envolver, como numa poça de goma de mascar, as articulações emocionais dos apreciadores"*. Para Anatol, é insuficiente definir o kitsch como "mau-gosto"; ele seria a arte da indolência e do entorpecimento. A difusão maciça de clichês que o kitsch promove torna as nossas reações igualmente clicherizadas, a ponto de passarmos a ver a realidade estruturada por clichês. O kitsch seria parte integrante e determinante da alienação que nos assalta e envolve*.

Em 1951, Hermann Broch definiu o kitsch como "a conjunção do mel e do sangue”; essa conjunção se derrama, generosamente, no cinema e na política. Hitler e Nero foram adeptos fervorosos do kitsch ("fervoroso" já é um adjetivo kitsch), porque se empolgavam com o espetáculo de cristãos e judeus em chamas. A base das cerimônias políticas é kitsch em si mesma, misturando sempre mel e sangue. O kitsch traz aquele efeito de anacronismo dos faroestes - uma escaramuça entre caubóis e índios rebeldes devidamente acompanhada por música sinfônica - ou da arquitetura monumental pós-moderna - um enorme arranha-céu com o topo em forma de templete grego ou de pirâmide asteca. Mas os principais artistas kitsch, para Juan José Saer, são os políticos que interpretam vários papéis, lêem textos escritos por outros e trocam de roupa, e de comportamento, conforme as circunstâncias*.

Nesse caso, todavia, o problema residiria menos na metáfora em si, e mais no esquecimento da sua condição - para usar neologismo feio, na sua "catacresização" e posterior "kitschização”. Um dos metaforismos (mistura de metáfora com aforismo) de Augusto Roa Bastos estabelece: “a palavra diz
" (Rosenfeld, Anatol. Texto/ pectiva, 1993: 292.) 
(Bastos, Augusto Roa. Meta(Brismos. Buenos Aires: Seix Barral, 1996: 39.)

Cacaso. Lero-lero. Rio de Janeiro: 7 Letras; São Pau lo: Cosac \& Naify, 2002: 31.)

"Man, Paul de. "A epistemo. logia da metáfora". Em: Sacks, Sheldon (org.). Da metáfora. Ob.cit.: 32.) a verdade uma única vez; pronunciada duas vezes, a nega"* Em conseqüência, compete à poesia recuperar metáforas esquecidas, "descatacresizando-as" - como ocorre no poema "Livre-arbítrio":

Todo mundo é toureiro.

Cada um escolhe o touro que quiser na vida.

$\mathrm{O}$ toureiro escolheu o próprio touro.*

O touro, metáfora ibérica do inimigo íntimo (mais: metáfora da natureza aterrorizante ou de Dionísio, o deus-animal), retorna na poesia como a própria coisa - como o próprio touro. O mesmo Cacaso recupera outras metáforas, retransformando nomes de doces típicos, usuais em festas de casamento, no sentido de seus símiles originais, e permitindo que os quatro versos do poema "Bodas" construam toda uma narrativa, se não trágica, triste:

Bombucado

Casadinho

Suspiro

Brevidade*

O namoro é de fato e de direito um bom bocado que leva ao casamento, o qual, por sua vez, provoca um suspiro: onde está o que estava tão bom? Sempre é breve - mas ao menos nenhum dos momentos, segundo essa narrativa ela mesma brevíssima, aparece como menos do que doce.

Para Paul de Man, a distinção entre julgamentos “apenas pode ser estabelecida por meio de metáforas que são elas mesmas simbólicas”* Entra-se no círculo vicioso que desde antigamente os céticos têm reconhecido nas tentativas de conhecimento e ciência. $\mathrm{O}$ conhecimento do conhecimento está destinado a permanecer simbólico, aludindo ao que se pode saber, mas não se sabe. Dessa constatação não se pode deduzir, todavia, que não há conhecimento. Quem toma o que conhece por já dado (dado por Deus ou pela realidade) incorre no pecado da reificação (figura oposta à da prosopopéia), coisificando eventos e fenômenos que seriam dinâmicos. Todavia quem pensa o contrário, isto é, quem pensa que a linguagem é simbolismo puro e os referentes, meras ilusões lingüísticas, termina por incorrer no pecado do esteticismo, isto é, comete uma espécie de reificação invertida. 
Dito de outro modo: dizer que toda a linguagem é metafórica e que, portanto, tudo o que damos por conhecido é ficção não implica dizer que o real não existe, mas apenas que não temos acesso pleno ao real. Em outras palavras, o problema não está resolvido. Segundo Paul de Man, por ser dependente da figuração, toda a filosofia estaria condenada a ser literária; pelo mesmo foco, toda literatura é até certo ponto filosófica. A simetria das afirmações não tranqüiliza, pois o que parece aproximar a literatura da filosofia é antes "uma ausência recíproca de identidade ou especificidade”* Isso é necessariamente ruim? Talvez não.

É preciso, como Kafka, usar metáfora contra metáfora; é preciso, como o toureiro, escolher o próprio touro. A metáfora, quando a percebemos como o que é, parece convidar o leitor a deixar de lado a realidade familiar, para vê-la sob uma perspectiva diferente, permitindo-se ver novamente o touro que mal havia visto. Isso não implica adotar "visão mais profunda" sobre a realidade, mas sim esboçar uma realidade provisória. Apontam-se pela linguagem armas contra a própria linguagem, em primeiro plano, e contra a realidade mesma, em segundo plano. É esse poder renovador e transformador da metáfora que faz com que ela também encontre defensores ardorosos. Um deles é José Ortega y Gasset. O filósofo espanhol mostrou-se fascinado pelo poder das metáforas, referindo-se a elas como instrumentos que quebram a referencialidade da linguagem e a livram de sua função ontológica, permitindo-nos esquecer do mundo:

A metáfora é provavelmente a potência mais fértil que o homem possui. Sua eficiência chega a tocar os confins da dramaturgia e parece um instrumento de criação que Deus deixou esquecido dentro de uma de suas criaturas na hora de fazê-la, como o cirurgião distraído que deixa um instrumento no ventre do operado. Todas as outras potências nos mantêm inscritos dentro do real, do que já é. O que mais podemos fazer é somar ou subtrair umas coisas de outras. Só a metáfora nos facilita a evasão e cria entre as coisas reais recifes imaginários, florescimento de ilhas sutis."

Para definir a metáfora, Ortega y Gasset recorre, como não poderia deixar de ser, à metáfora - no caso, às metáforas combinadas de Deus e do cirurgião distraído, para chegar ao símile geográfico dos recifes imaginários, ou das ilhas sutis. O leitor atento percebe a oscilação; talvez, uma contradição: ora se deve resistir às metáforas porque elas liquefazem o 
"(Tyniánov, lúri. O tenente Quetange. Tradução de Auro Bernardini. São Paulo: Cosac \& Naify, 2002: 27.) sentido, ora as metáforas se tornam armas contra a liquefação do sentido e inauguram significados no meio de sentidos reificados. Nesse caso, a oscilação e a contradição desvalorizam a metáfora como instrumento capital de conhecimento ou então o conhecimento não pode deixar de oscilar entre contradições - quando a metáfora seria, sim, um instrumento capital de conhecimento. Suponho, como o leitor pode depreender, que a segunda alternativa nos deixe mais próximos da verdade.

Para melhor se descatacresizar a metáfora, devolvendolhe seu poder transformador e renovador, pode-se levá-la a sério "demais", isto é, ao pé da letra - "pé" que, por sua vez, é outra metáfora. Encontramos um excelente exemplo de metáfora levada ao pé da letra no divertido romance $O$ tenente Quetange, de Iúri Tyniánov. O romance começa no momento em que um escrivão do Imperador, em vez de escrever na ordem-do-dia "a nomeação para tenentes que tange a Stíven, Rybin e Azantchéiev foi determinada”, escreve: "a nomeação para tenentes Quetange, Stíven, Rybin e Azantchéiev foi determinada”*. A tradução do russo para o português mantém o efeito cômico: a expressão oracional "que tange" se torna o nome próprio "Quetange". Como o Imperador assina a ordem-do-dia, ela deve ser cumprida, no entanto a ordem simplesmente não pode ser cumprida porque, afinal de contas, não existe no regimento nenhum tenente Quetange. Sem saber o que fazer, o comandante leva o problema ao assustado ajudante do Imperador; o ajudante do Imperador, também sem saber o que fazer, acaba determinando que o Comandante considere como existente o tenente Quetange, designando-o para a guarda.

Mais tarde, acusado de um delito que ninguém sabia a quem acusar, o inexistente tenente Quetange é condenado a receber sete chibatadas - os soldados, constrangidos, aplicam as chicotadas na madeira do cavalete destinado a esse fim e, depois, escoltam o degredado à Sibéria: "E lá se foram eles pela rua, fuzil no ombro, afastando-se do regimento a passos regulares, lançando de vez em quando um olhar de esguelha, não um para o outro, mas para o intervalo entre ambos"*. Essa descrição do movimento constrangido dos soldados é, mais do que hilária, emblemática da potência paradoxal da metáfora. 
Depois de vários episódios patéticos, o tenente Quetange é perdoado e retorna ao Regimento, sendo promovido a capitão e depois a coronel. Como o coronel Quetange não pedia terras, não vivia atrás de favores, não adulava nem lisonjeava ninguém, rapidamente é alçado ao posto de general. Informado do seu ilibado caráter, o Imperador manifesta o desejo de falar com ele, mas lhe informam que o general se encontra gravemente enfermo. O Imperador ordena que o internem e o curem: "na grande enfermaria, a portas fortemente fechadas, os médicos não sabiam o que fazer, tremiam como os doentes"*. Finalmente, eles encontram a solução: o general Quetange falece. Os funerais impressionam São Petersburgo. Suas condecorações são levadas em almofadas, num cortejo. O Imperador lamenta: "Morrem-me os melhores homens"*.

Além da divertida expressão "morrem-me", lógica para um Imperador que se considera no centro do universo, podemos aproveitar a sua fala para acrescentar uma moral à história de Tyniánov e a este artigo: os melhores homens são apenas metáforas. 


\section{Gustavo Bernardo}

Doutor em Literatura Comparada pela Universidade do Estado do Rio de Janeiro (1995) e professor de Teoria da Literatura em regime de dedicação exclusiva na mesma universidade. Desenvolve pesquisa sobre as relações entre literatura e ceticismo, da qual faz parte o presente artigo. Essa pesquisa é financiada por uma Bolsa de Produtividade em Pesquisa do CNPq. Publicou, entre outros títulos, Lúcia (Relume Dumará, 1999); Educação pelo argumento (Rocco, 2000); A dúvida de Flusser (Globo, 2002), que recebeu o Prêmio Jabuti - Menção Honrosa, na categoria “Teoria da literatura”, em 2003. Acaba de publicar, pela editora Annablume, o ensaio "A ficção cética”.

Palavras-chave metáfora epistemologia teoria da literatura

Mots-clés métaphore epistémologie théorie de la littérature

Key words

metaphor epistemology literary theory

Recebido em 25/09/2003 Aprovado em
$30 / 11 / 2003$

\section{Resumo}

Investigação do poder ambivalente da metáfora como agente do conhecimento: ora se deve resistir às metáforas porque elas liquefazem o sentido, ora as metáforas se tornam armas contra a liquefação do sentido e, então, inauguram significados em meio aos sentidos reificados.

\section{Résumé}

Investigation du double pouvoir de la métaphore en tant qu'agent de la connaissance: tantôt il faut résister aux métaphores parce que celles-ci liquéfient le sens, tantôt les métaphores deviennent des armes contre la liquéfaction du sens et, alors, elles inaugurent des signifiés parmi les sens réifiés. 